\title{
Twin pregnancy one neonate with encephalocele
}

\begin{abstract}
Encephalocele is neural tube defect characterized by failure of the surface ectoderm to separate from the neuroectoderm. This leads to a bony defect in the skull table, which allows herniation of the meninges or brain tissue.1,2 To report case of 30 years old gravida 5 para 3 abortion 1 lady admitted with diagnosis of twin pregnancy and one of the twin with neural tube defect, delivered one health neonate and other with encephalocele. Conclusion folic acid supplementation and/or food fortification for all reproductive age groups will reduce incidence and recurrence of neural tube defect according to the level of the risk they have.
\end{abstract}

Keywords: twin pregnancy, encephalocele, neuroectoderm, herniatio

\author{
Volume 4 Issue 2 - 2018
}

\author{
Takele Digafe,' Tariku Wakuma, ${ }^{2}$ Alemayo \\ Beyene $^{3}$ \\ 'Obstetrician and Gynecologist, Aira General Missionary \\ Hospital, Ethiopia \\ ${ }^{2}$ Surgical Expert, Aira General Missionary Hospital, Ethiopia \\ ${ }^{3}$ Emergency Surgeon, Aira General Missionary Hospital, Ethiopia
}

Correspondence: Takele Digafe Diriba, Obstetrician and Gynecologist, Aira General Missionary Hospital, Ethiopia, Email d.takele@yahoo.com

Received: February 19,2018| Published: April 16, 2018

\section{Introduction}

Encephalocele is neural tube defect characterized by sac like protrusions of the brain and the membranes that covers it through openings in the skull. It results from failure of the surface ectoderm to separate from the neuroectoderm. This leads to a bony defect in the skull table, which allows herniation of the meninges or of brain tissue.

\section{Case report}

30 years old gravida 5 para 3 abortion 1 lady referred from local health center with diagnosis of twin pregnancy and latent 1st stage of labor. On arrival to hospital large for date gravid uterus, multiple fetal part were palpable, two sites fetal heart beat was heard. Twin pregnancy was identified 1st cephalic, within normal range both fetal heart beat, three contractions in ten minute that stayed fifty to sixty second. During pelvic examination cervix was $8 \mathrm{~cm}$ dilated, vertex, left occiput anterior, station on +1 . Ultrasuond was done; the 1 st twin was positive fetal heart beat, biparietal was $9.4 \mathrm{~cm}$, cephalic and the second twin was breech, positive fetal heart beat, $7.1 \mathrm{~cm}$ biparietal diameter, occipital area of skull defect with protruded mass of $9 \times 10 \mathrm{~cm}$ in diameter contains fluid.
She had antenatal care follow up at local health center and hospital; ultrasound was done once in the same hospital and told her that twin pregnancy with one in good condition but the 2 nd twin had skull defect with protruded mass at gestational age of 1st twin BPD of 25 week plus three days. After stayed two hours in hospital she gave birth of 1st twin spontaneously female neonate, weighing $2400 \mathrm{gm}$ and APGAR score of seven and nine at 1 st and 5 th minute respectively. The 2nd twin was delivered after ten minute of the 1 st twin delivered with finding of male neonate weighing 2000gm with APGAR score four, five and five at $1 \mathrm{st}$, 5 th and 10 th minute respectively. The placenta was two separated placenta of diamniotic dichorionic placent. Neonate had skull defect on occipital area with protruded mass .with diagnosis of neural tube defect (encephalocele) neonate managed and after 14hours stayed, neonate was died by respiratory failure. Her body mass index was $22.6 \mathrm{~kg} / \mathrm{cm}^{2}$ and she was investigated for diabetic, random blood sugar level was in normal range. The mother and the first neonate was discharged in good condition after contraceptive was given on second post-partum day (figure 1).
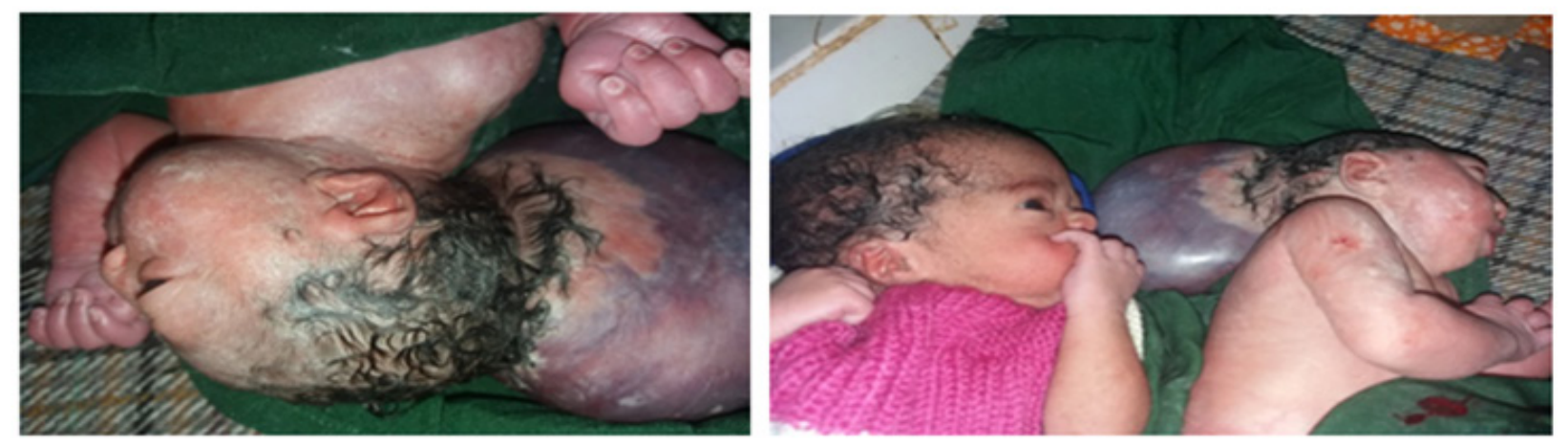

Figure I The mother and the first neonate was discharged in good condition after contraceptive was given on second post-partum day. 


\section{Discussion}

Encephalocele is neural tube defect which includes abnormalities in skull, scalp, and brain tissue formation. These conditions are lethal, except small encephaloceles. ${ }^{1}$

Even though the prevalence of neural tube defect is not well known in sub Saharan countries, prevalence-at-birth of neural tube defect was $1.6 / 1,000$ twin births, which is significantly higher than the singleton prevalence of $1.1 / 1,000$ births in USA. The prevalence of encephalocele in total birth was 0.41 and in singleton was 0.08 .the prevalence of encephalocele in neural tube defect was $15 \% .^{2}$ Male to female ratio of encephalocele in twin was 0.17 , in singleton was 1.03 . The prevalence of both encephalocele and anencephaly are increased, whereas spinal bifida is decreased in twin birth.,

The main risk factor in our set up considered as lack of folic acid supplementation and/or food fortification, even if the presence of other factors like environmental toxicants, cannot be excluded..$^{1-3}$

Abnormal folate metabolism was responsible for many neural-tube malformations. A thermolabile variant of the enzyme, ${ }^{4}{ }^{10}$-methylene tetrahydrofolate reductase (MTHFR), which plays a key role in folate metabolism, was shown to be associated with neural-tube defects. This enzyme transfers a methyl group from folic acid to convert homocysteine to methionine. One abnormal form of MTHFR carries a mutation at position 677 of its gene and has reduced enzymatic activity. Folic acid supplementation likely works by overcoming this relative enzyme deficiency. Because some defects develop in fetuses with normal $677 \mathrm{C} \mathrm{T}$ alleles, and because folic acid supplementation does not prevent all cases, other unknown genes or factors are presumed to be involved.5-7

Literature indicated that encephaloceles are often will have microcephaly (abnormal small head) similar to this case had small head some part of brain tissue was extruded through the defect and other will have craniofacial abnormalities or other brain malformations. ${ }^{2,8}$

In our set up screening method by maternal serum alpha-fetoprotein is not widely available and early diagnosis does not change the outcome of this case, but obstetric ultrasonography report excellent sensitivity and specificity in detecting fetal neural tube defects, especially in high-risk patients, and many hospital or diagnostic center offer specialized ultrasound examination as a diagnostic test for women at high risk of neural tube defects., ${ }^{9,10}$

The fetus with neural tube defect should be delivered at term when lung maturity is well established. In this case a neural tube defect was diagnosed during antenatal care follow up but delivery was delayed for achieving lung maturity of health fetus. Literature recommended that fetus with neural tube defect complicated by enlarged head, spinal bifida, neurological dysfunction and breech presentation, cesarean delivery is standard. ${ }^{11}$ The delivery should be at hospital with neonatal intensive care unit and personnel capable of managing the complications for better outcome. ${ }^{12}$ Even though we don't have such set up, this is lethal congenital malformation; we cannot change the outcome of the malformed one even if she had delivered at best facilities.

The recurrence risk of neural tube defect after one affected child is 3 to 4 percent, and after two affected children is 10 percent without folic acid supplementation. With folic acid supplementation, the risk of recurrence after one affected child decreases by 70 percent to less than 1 percent .It currently is recommended that women of reproductive age take a $400 \mu \mathrm{g}$ folic acid supplement daily before conception and at least through the first 4 weeks of fetal development to be effective. Consumption of $400 \mu \mathrm{g}$ folic acid per day for women at low risk would reduce the incidence of NTDs by $36 \%$, the $4 \mathrm{mg}$ folic acid per day, for women at high risk, would reduce the incidence of neural tube defect by $82 \%$, and a $5 \mathrm{mg}$ folic acid would reduce the incidence by $85 \%{ }^{6,7}$

Neural tube closure is normally complete by the end of the fourth week after conception ( 6 weeks after the last period), a time when many women do not yet realize they are pregnant. ${ }^{1,2}$

\section{Conclusion}

On conclusion folic acid supplementation and/or food fortification for all reproductive age groups will reduce incidence and recurrence of non syndromic neural tube defect according to the level of the risk factors.

\section{Acknowledgements}

None.

\section{Conflict of interest}

There is no conflicts to publish the article in this Journal.

\section{References}

1. ACOG Committee on Practice Bulletins. ACOG practice bulletin Clinical management guidelines of neural tube defect for obstetriciangynecologists. Obstet Gynecol. 2003;102(1):203-213.

2. Nicholas DE, Greene, Andrew J. New life birth defects research center Institute of Child Health, University College London, WC1N 1EH, United Kingdom, 2014;37:221-242.

3. Windham GC, Sever LE. Am J Hum Genet. 1982;34(6):988-998.

4. Williams Obstetrics. 23e.Chapter 13. Prenatal Diagnosis and Fetal Therapy. Neural-Tube Defects; 2001.

5. Cuckle H, Wald N, Stevenson JD, et al. Maternal serum alpha-fetoprotein screening for open neural tube defects in twin pregnancies. Prenat Diagn. 1990;10(2):71-72.

6. ACOG practice bullentin. ACOG Practice Bulletin No. 43. American College of Obstetricians and Gynecologists. Obstet Gynecol. 2003;101:697-706

7. Wald NJ, Law MR, Morris JK, et al. Quantifying the effect of folic acid Lancet. 2001;358(9298):2069-2073.

8. Copp AJ, Greene NDE. Genetics and development of neural tube defects. J Pathol. 2010;220(2):217-230.

9. Lennon CA, Gray DL. Sensitivity and specificity of ultrasound for the detection of neural tube and ventral wall defects in a high-risk population. Obstet Gynecol. 1999;94(4):562-566.

10. Milunsky A. Maternal serum screening for neural tube and other defects. In: Genetic disorders and the fetus: diagnosis, prevention, and treatment. 4th ed. Johns Hopkins University Press; 1998:635-701.

11. Cochrane D, Aronyk K, Sawatzky B, et al. The effects of labor and delivery on spinal cord function and ambulation in patients with meningomyelocele. Childs Nerv Syst. 1991;7(6):312-315.

12. Wilkins-Haug L. Considerations for delivery of infants with congenital abnormalities. Obstet Gynecol Clin North Am. 1999;26(2):399-412. 